\title{
LA HORA DEL ESPECTADOR: \\ DE LA ERA DEL AUTOR DRAMÁTICO \\ A LA DEMOCRATIZACIÓN DEL SIGNIFICADO DE LA ESCENA
}

\author{
THE TIME OF SPECTATOR: \\ FROM THE ERA OF THE PLAYWRIGHT \\ TO THE DEMOCRATISATION OF THE MEANING \\ OF THE STAGE
}

\section{Mariángeles RODRÍGUEZ ALONSO}

\author{
Universidad de Murcia \\ mariangeles_ra@hotmail.com
}

Resumen: Hacia la mitad de la década de los setenta, la escena constituye ya un lugar de integración y diálogo entre los diferentes lenguajes escénicos. Emancipados, pues, los diferentes códigos, será el espectador interpretante el que se sitúe en el centro, como fuerza activa y dinámica. A la era del dramaturgo sucede la del director $y$, a esta, la del espectador como responsable último de la unidad de sentido de la polifonía de signos que converge en la puesta en escena. El empleo de la semiótica y la semiología en el examen de las nuevas propuestas escénicas revela asimismo el protagonismo del espectador en la articulación del discurso crítico sobre la escena.

Palabras clave: Espectador. Escena. Semiótica. Crítica teatral 


\begin{abstract}
In the middle seventies, the stage became a place of integration and dialogue of different scenic languages. The codes get their autonomy. The spectator and his ability to interpret take the centre as dynamic and active strength. The age of the author is followed by the age of the stage director, and this is ensued by the age of the spectator as element responsible of the unit of sense of the polyphony of signs that converge on the staging. The use of semiotics and semiology in the exam of the new performances reveals the prominence of the spectator in the articulation of the critical discourse on the stage.
\end{abstract}

Key Words: Spectator. Stage. Semiotics. Theatre critiscism.

\title{
1. UNA TRASLACIÓN EN LA CONCEPCIÓN DE LA ESCENA
}

En un trabajo anterior abordamos el análisis de las modulaciones del discurso crítico sobre el teatro desde la mitad del franquismo hasta la democracia. Partíamos entonces del convencimiento de que si la arquitectura de un discurso denota la construcción de mundo que subyace tras él; en el análisis del discurso sobre el teatro hallaríamos las claves de la concepción teatral de cada tiempo. Afrontamos así el examen de diversos ensayos, noticias y artículos sobre diversos elementos teatrales en una primera parte, y el análisis de un corpus cerrado de críticas teatrales en un segundo momento del estudio, constatando, tal y como trataré de revelar en el presente artículo, una transformación esencial en el discurso sobre lo teatral: el paso de del centro de la atención desde el autor dramático (como responsable del significado del mensaje) hacia el espectador (como responsable de la otorgación de sentido al mensaje artístico a través de su recepción). Paralela a esta resulta la traslación de las poéticas realistas de la escena de los cincuenta hacia una concepción sensorial y fenomenológica 
de la misma en la que prima su naturaleza comunicativa a partir de apuestas escénicas formuladas desde el teatro independiente. La tesis que proponemos viene a visibilizar, por tanto, el sentido nuevo de la puesta en escena que nace hacia finales de los años sesenta en el panorama español, esto es, lo que desde el título de esta intervención hemos convenido en llamar la hora del espectador. El movimiento se produce, como venimos anunciando, desde una concepción textocentrista del fenómeno teatral, propia de poéticas realistas dependientes del orden referencial externo, a una concepción espectacular en la que los diferentes lenguajes se independizan conquistando su autonomía artística y expresiva, libres ya de la subordinación servil al texto.

A lo largo del análisis de la conversación que se genera en torno a la escena comprobamos que no obedece el cambio a un despertar simultáneo de todos los lenguajes, sino que diversos acontecimientos históricos - la llegada de ciertas teorías, la actuación de un grupo extranjero o la propia evolución de nuestras formas por innovación o agotamiento- propician y exigen la vindicación de determinado elemento en un momento concreto. El motor de la renovación se hace cambiante a lo largo del proceso. Constatamos así cómo el elemento tensor de la renovación de la escena se halla, en un primer momento, en la figura del director y en la emancipación del concepto de puesta en escena que este consigue; del director pasa el protagonismo al actor como único elemento imprescindible para la comunicación dramática con el espectador; y de este, a la reivindicación del espacio escénico como lugar definitorio y determinante de la propuesta dramatúrgica en el que conviven los distintos códigos con plena autonomía. Vemos por tanto cómo los diversos lenguajes escénicos, relegados hasta el momento a un lugar accesorio e ilustrativo, van reclamando un lugar en el discurso. Se produce en este horizonte un proceso de semiotización de los elementos convergentes en la escena, es decir, una paulatina conversión en sistemas sígnicos que desembocará en la creación de una gramática escénica. El cuerpo del actor, la luz, las líneas que subraya la escenografía se convierten en escrituras dramáticas equiparables a la escritura lingüística 
del dramaturgo que hasta el momento ha ostentado el centro y la práctica exclusividad como sistema sígnico.

\section{LA PROBLEMATIZACIÓN DEL AUTOR DEL TEXTO ARTÍSTICO EN LA CRÍTICA TEATRAL}

La cuestión de la autoría en un fenómeno tan plural e interdisciplinar como el teatro, entraña una enorme complejidad. Las responsabilidades de las labores creativas de dramaturgos, directores, actores, escenógrafos, figurinistas, luminotécnicos y demás creadores se entrelazan en el todo indivisible que constituye la puesta en escena, el objeto artístico en cuestión. La complejidad hace más interesante la búsqueda de las soluciones que adopta la crítica del periodo que nos ocupa a este problema. Nos interesará en el examen hallar quién, a juicio de los críticos, es el máximo responsable del acontecimiento escénico, esto es, del objeto artístico que recibimos cuando asistimos a una representación, y observar si existen cambios o mutaciones en esta percepción. En los titulares de las críticas hallamos importante información al respecto, ya que reflejan la huella del cambio en esta cuestión. Responden los de $A b c$ a una estructura fija: título de la obra seguido del autor de la misma, seguido a su vez del teatro o sala de representación: "Jueces en la noche, de Buero, en Lara", "Cara de plata, de Valle Inclán, en el teatro Beatriz" o "Mariana Pineda, de García Lorca, en el Marquina”, serían tres ejemplos. Esta estructura nominadora es síntoma de la prevalencia del autor sobre los demás creadores. Sin embargo, algunas de las variaciones que presentan resultan significativas y reveladoras del cambio que se opera. El título de la crítica de $A b c$ a la Yerma que se representa en diciembre de 1971 en el teatro de la Comedia es elocuente a este respecto: "Yerma, de Víctor García, en la Comedia" (Prego, 1971). Como vemos, el director suplanta el lugar protagonista correspondiente al dramaturgo. El autor de la crítica, Adolfo Prego, subraya además el contenido del título en el cuerpo del texto: "No hay error en el título de la crónica. Esta Yerma es más del director Víctor 
García que de García Lorca" (Prego, 1971). Desde Triunfo, bajo el titular "Yerma, el teatro de lo insólito" (Monleón, 1971: 38), comenta Monleón el poder transformador que introduce Víctor García en la jerarquía del espectáculo:

Se diría que Victor García introduce una nueva jerarquía en la poética del espectáculo teatral. Lo fundamental en su caso es el hallazgo de unas imágenes visuales y sonoras, tremendamente sugestivas, que aparecen como el eco que en Victor García despiertan los textos (Monleón, 1971: 38).

El particular montaje que realiza Facio a partir de La casa de Bernarda Alba, reaviva la polémica sobre la autoría del espectáculo. La crítica a este espectáculo desde El País, evidencia asimismo la reestructuración de jerarquías que se pretende desde el titular con el que el crítico la encabeza: "Devorar a García Lorca" (Llovet, 1976a). La lectura que Llovet realiza de Lorca dista de la de Facio y así lo manifiesta:

No le niego a Facio su derecho a disentir. Nadie podrá negarme a mi el de preferir. Prefiero Lorca, las intenciones de Lorca, las órdenes teatrales de Lorca, a las de Facio. No por un vago respeto al autor. Sino porque encuentro gratuito y snobizante el travestí, porque (...) porque el texto se ahoga; porque la meditada dramaturgia lorquiana se abola con los ridículos destapes: porque todo un delicado equilibrio se humillaba o los brutales zamarreros y los atroces subrayados de una dirección que quiere competir con Victor García devorando sin contemplaciones a Federico García Lorca (Llovet, 1976a).

Sin embargo, y ahí se halla la modernidad de su crítica, afirma: "Yo 
aplaudiré una y cien veces a este tipo de esfuerzos. Trataré de entender todas las propuestas y discursos escénicos que clarifiquen y reactiven los significados más escondidos. Pero, después, elegiré" (Llovet, 1976a). No es el procedimiento lo que ataca con su crítica sino un resultado no acorde con su visión del drama.

Otro de los casos más llamativos en cuanto a la subversión de las jerarquías tradicionales y la distinta consideración suscitada entre la crítica es, sin lugar a dudas, el montaje de Divinas palabras que realiza Víctor García en 1977. Desde el titular de la crítica de $A b c$ es la actriz empresaria la que ostenta el lugar protagonista ("Divinas palabras, de Valle Inclán, por la compañía de Nuria Espert”) permaneciendo aún tanto el título de la obra como el del dramaturgo. Arjona, equipara en lugar y protagonismo a los tres creadores: Valle Inclán, Víctor García y Nuria Espert.

Unidos tres nombres cimeros, cuales son los de don Ramón María del Valle-Inclán, Nuria Espert y Víctor García, en un mismo programa no es extraño que la sala del teatro Álvarez Quintero se llenara de un público ansioso de recibir a través de sus sentidos las ideas de las que son portadores esos tres excepcionales artistas: Valle-Inclán, el Fidias del verbo; Nuria Espert, la actriz de mayor profundidad trágica del presente español, y Victor García, el director que ha logrado... (Arjona, 1976).

Desde la Gaceta Ilustrada se da un paso más. Lázaro Carreter titula la crítica, "Divinas palabras, espectáculo de Víctor García" iniciándola con este irónico y lacerante comienzo:

"Con este título que coincide con el de una famosa tragicomedia de Valle-Inclán se ha representado en el Monumental de Madrid, por la compañía de Nuria Espert, un espectáculo di- 
rigido por Víctor García”. Así pensé iniciar esta crónica pero he renunciado a ello porque no hubiera sido justo. Poniendo mucha atención, tapándose los oídos y cerrando los ojos, puede percibirse que el texto de Divinas palabras pasa casi integro por las forzadas laringes de los actores. No se trata pues de una coincidencia [...] El director triunfa, el director pasma, el director alza su nombre sobre el de todos, y, al final, más que aplaudir, lo que el público debería hacer es gritar enfervorizado que viva el director (Lázaro Carreter, 1977).

Muy interesante resulta la comparación en este sentido de esta crítica con la de El País, ya que describiendo el mismo acontecimiento e incidiendo en los mismos aspectos de la propuesta, el tono y el talante de las críticas resultan radicalmente opuestos. Llovet excluye tanto el nombre de Valle como el de la pieza representada del titular de la crítica mediante la elíptica y oportuna fórmula "Espert-García ofrecen un monumental espectáculo" (Lázaro Carreter, 1977). Tras dicho titular en el que ya queda recogida la tesis principal, comienza la crítica con la siguiente enumeración retórica: "Monumental teatro, monumental actriz, monumental espectáculo". Mediante una estructura de estirpe retórica, principia cada uno de los párrafos siguientes con uno de los sintagmas de la yuxtaposición. En el dedicado a la figura del director comprobamos una radical revalorización de la misma:

Monumental director. Victor García tiene una gran capacidad para visualizar subjetividades. Es un genial arquitecto que utiliza madera, metal, luz y seres humanos para construir sus faraónicas propuestas [...] los textos le resultan accesorios ya que concede la gloria creadora al director y no al autor. [...] En estas condiciones se salvan el teatro, la actriz y el director con su espectáculo (Lázaro Carreter, 1977). 
La única alusión en toda la crítica al texto de Valle Inclán queda circunscrita al último párrafo viniendo además recogida entre paréntesis. La reproducimos a continuación:

(Una última y mínima nota que quizás sólo interesase a algunos raros curiosos o a ciertos testarudos eruditos: estas maravillas han sido levantadas, según los programas, utilizando como vago pretexto un texto de don Ramón del Valle-Inclán, Divinas palabras, que puede consultarse fácilmente en cualquier librería, incluso en las cercanas al teatro. Lástima que el señor García no lo haya hecho...) (Lázaro Carreter, 1977).

Se deduce, por tanto, de la confrontación de ambas críticas la existencia de dos concepciones teatrales radicalmente opuestas: una textocentrista en la que el valor supremo se halla instalado en el texto y, por tanto, el responsable máximo sería el autor dramático; y otra, naciente, en la que el centro viene ostentado por el espectáculo y la poética escénica que se genera, quedando en un lugar muy secundario el autor respecto al director escénico que se alza con la soberanía del espectáculo. Podemos constatar, tras el examen de los elementos señalados, la evolución desde una posición en la que el autor ostenta la hegemonía creativa y, por tanto, el centro de la atención — se repasa su trayectoria artística, se ponderan sus grandezas, solo existe una posible lectura de su obra, la ideal y más fiel al texto mismo - a una situación en la que el director pugna frontalmente contra el autor en la conquista de su consideración como creador.

Un ejemplo más evidencia la transformación. El arranque de la crítica de Doña Rosita, la soltera deviene indicativo de un estado de cosas que otorga al autor un lugar distinto del hegemónico e incontestable que venía ocupando: 
El autor sólo conoce en parte el sentido o los sentidos que alcanzará su obra [...] sobre todo porque, irremediablemente, cada época, cada ideología, cada director de escena, e incluso, cada espectador, según las circunstancias, verán la obra de un modo distinto (Monleón, 1980: 27).

Estas afirmaciones evidencian cierta democratización del sentido último de un texto que desde buena parte de la crítica se juzgaba posesión exclusiva del autor del mismo. En esta misma crítica, Monleón aborda el análisis desde la perspectiva del director de la obra, ya que a su juicio ha sido "Lavelli quien [...] ha descubierto en Doña Rosita, la soltera las dimensiones que mejor justifican su estructura dramática $\mathrm{y}$, a la vez, aclaran la modernidad" subrayando en la crítica que comentamos las cinco "iluminaciones fundamentales" que ha logrado el director mediante su puesta en escena (Monleón, 1980: 32). El mismo título de la crítica, "La visión de Lavelli" es muy revelador al respecto. No solo interesa ya García Lorca según García Lorca —o según los académicos que puedan desentrañar el sentido que el autor encerró en su texto-; sino García Lorca según Lavelli, esto es, la lectura creativa e iluminadora que el director hace del texto del autor en la nueva emisión del mismo que supone su puesta en escena. Tras el análisis pormenorizado de las claves de lectura que rigen la puesta en escena del director argentino, concluye Monleón: "Eso estaba en Lorca. Pero ha sido Lavelli quien lo ha clarificado sobre el escenario" (Monleón, 1980: 36).

\section{LA PERCEPCIÓN DE UNA NUEVA COMUNICACIÓN DESDE LA CRÍTICA TEATRAL}

Procedemos seguidamente a dar cuenta de las huellas que quedan en la crítica teatral de los cambios operados en el proceso de recepción que constituye la representación teatral. Desde el análisis del discurso crítico se evidencia el nacimiento de un nuevo tipo de comunicación desde la 
escena. Comprobamos así cómo resulta altamente frecuente, el arranque de la crítica desde la explicitación de las condiciones de recepción de la obra. Los lugares comunes de este comentario serían: la descripción del ambiente de la representación; la constatación de la mayor o menor afluencia de público; la descripción de las características del público asistente (edad, estatus social, etc.); el reflejo de la respuesta del público (silencio, risas, aplausos, abucheos, etc.); y la noticia del saludo del autor o de discurso del mismo, si lo hubiere. Ejemplos de esto podría ser el caso de la crítica de La enamorada del rey, en la que Monleón constata: "el público responde. Y aplaude. Y baja de golpe la edad media de nuestros espectadores teatrales" (Monleón, 1967: 59). O desde la Gaceta Ilustrada, la crítica de La marquesa Rosalinda que se detiene en la descripción de la escasa afluencia de público, así como de sus reacciones:

en una ocasión, por tanto, más que propicia para un lleno total. Pero el público no ocupaba más allá de un cuarto de la sala; y aunque los aplausos finales rebasaron levemente los parcos límites de la cortesía, el alma de un admirador ferviente de Valle-Inclán - tal es mi caso- tenía que asistir en sus senos, camino del lar doméstico, una penosa sensación de frí y perplejidad (Laín Entralgo, 1970: 20).

Sin embargo, este comentario sobre la recepción convive con otro de índole distinta. En un segundo momento, sobre todo a partir de la llegada a los escenarios de los grupos independientes, se hace habitual dentro de la crítica la reflexión sobre las condiciones de la comunicación que instauran determinadas puestas en escenas cada vez más recurrentes. El crítico percibe así un cambio en la recepción del espectáculo y ahonda en la explicitación de los factores intervinientes en la nueva situación en la que la relación actor-espectador se hace nuclear. Constata de este modo el crítico: a) el papel activo el espectador en las nuevas condiciones de 
recepción; b) la descripción del ambiente festivo o ceremonial que favorece la comunión entre actores y público; c) la potenciación de la vía emotiva y sensorial frente a la argumental y racional del teatro convencional; d) la alusión al carácter de acontecimiento político de la representación; y e) la complicidad con el espectador, esencial en el desentrañamiento de la significación de la propuesta escénica. Nos detendremos en algunos de estos aspectos para ilustrar el cambio al que asiste el fenómeno teatral.

\subsection{Un nuevo espectador teatral}

Se percibe desde la crítica un nuevo lugar para el espectador teatral, más activo y más partícipe en la nueva comunicación que se inaugura desde la escena. En la crítica a Mary D'Ous alude el crítico a la cooperación del espectador en la creación del propio mensaje así como al carácter abierto de los símbolos empleados en la escena:

pedir que Els Joglars concreten la significación de Mary d'Ous es negarse a una complicidad que tiene, en lo inmediato la imposibilidad de aclarar ciertas cosas, en un plano más profundo, la voluntad de que sean los espectadores quienes completen y desarrollen la significación de un lenguaje que necesita de su cooperación intelectual y vivencial. [...] es la misma materia comunicable la que debe ser creada por ambas partes, en vez de propuesta por una y aceptada pasivamente por la otra (Monleón, 1973: 69).

A esta misma cuestión alude la lúcida crítica de Francisco Nieva al mismo espectáculo de Els Joglars, aparecida en Primer Acto: 
La verdadera participación del espectador moderno empieza por ser una actividad receptiva, una voluntad integradora en el espectáculo que de algún modo se asemeje a la actitud que tomamos cuando intentamos iniciarnos a un lenguaje extranjero [...] Vamos poniendo en obra unas ciertas facultades adivinatorias, deductivas. Asi gozamos de la virginidad que ese lenguaje tiene para nosotros. Ese es uno de sus mayores encantos (Nieva, 1973: 4-8).

La imagen revela el misterio que circunda cualquier código artístico que por serlo es al tiempo exacto y desconocido. Las proximidades con los conceptos de indeterminación y concretización de Ingarden así como la estética de la recepción de Wolfgang Iser y Hans Robert Jauss son contundentes, hasta el punto de presentar cercanías léxicas con la teoría del primero y el concepto de los vacíos (blanks) propuestos por Iser. Pese a las fechas igualmente próximas, ${ }^{1}$ más que señalar una influencia pretendemos subrayar la confluencia o paralelo movimiento de campos críticos de notable proximidad.

\subsection{Una comunicación vivencial y fenomenológica}

Encontramos asimismo buenas muestras de la comunicación vivencialy fenomenológica que deviene la puesta en escena, particularmente desde las propuestas escénicas del teatro independiente, así como desde cierto sector del teatro privado con marcado carácter renovador. A propósito de Yerma de Víctor García, el comentario de Triunfo incide en la

\footnotetext{
${ }^{1}$ El 13 de abril de 1967, Jauss pronuncia un discurso o lección inaugural en la Universidad alemana de Constanza, que viene a ser el manifiesto o acta de fundación de la Estética de la Recepción. Este discurso se publica, poco después, con el título de La historia de la literatura como provocación a la ciencia literaria.
} 
enfervorecida recepción de la misma:

El espectáculo, recibido casi frenéticamente por el público, aplaudido a rabiar, suscitará el tipo de polémica que suele acompañar a los montajes de García. [...] parte del éxito se debe al carácter insólito del espectáculo, a su capacidad para golpear sensorialmente al público y transformar en excitación la cotidiana pasividad de las plateas (Monleón, 1971: 38).

Desde El País, el comentario crítico a Los Palos, Llovet incide en la naturaleza instintiva, ritual y primaria de la comunicación que este espectáculo provoca:

habla con tal autenticidad que el contacto con el espectador es algo fulminante. Esa vía tan primaria, esquemática y sobria es de una grandeza sobrecogedora y trasmite vitalmente al espectador todo el patetismo de las denuncias inexorables (Llovet,1976b).

En la crítica a Quejío, incide Jansa Anadón desde Pipirijaina "muchos tendrán ganas de coger esas cuerdas que La Cuadra nos ofrece y seguir estirando hasta que las piedras caigan en el patio de butacas. Entonces habrá concluido la función" (Jansa, 1974: 34). Esta imagen de enorme expresividad subraya el poder perlocutivo de la propuesta.

Alberto Miralles, en la crítica a Allias Serrallonga de Els Joglars reflexiona sobre las dificultades de la crítica para reflexionar sobre un teatro cada vez menos reducible a palabras. Señala así que:

una crítica no es bastante para informar sobre los hallazgos plásticos, sensuales, no literarios [...] supone reducir un len- 
guaje sensual a chata terminología racional. Y no se trata de retórica, aunque esta no se excluya, sino de semiótica y aún diría de semiótica abierta y relativa (Miralles, 1975: 92).

Comprobamos, por tanto, cómo la crítica percibe la insuficiencia de sus herramientas para el examen de las nuevas propuestas.

\section{LA NECESIDAD DE UNA PERSPECTIVA SEMIOLÓGICA PARA EL ANÁLISIS DE LA ESCENA: LA HORA DEL ESPECTADOR}

El hecho dramático ha cambiado, como también ha cambiado el modo de percibirlo. Hay, por tanto, un objeto nuevo, distinto de la enunciación del texto literario acompañado de una ilustración verista que suponía la puesta en escena realista. Los lenguajes escénicos se han desarrollado y han creado códigos no escritos. Existe una nueva gramática escénica que requiere ser indagada. Necesitamos, por tanto, un nuevo aparato crítico y metodológico que se adecúe a las necesidades del nuevo objeto. Es, por tanto, la aparición de la semiología teatral como disciplina el síntoma del cambio que se ha producido en la escena y en la concepción de la misma. Sin duda, el auge de la semiótica lingüística formalista en los años sesenta y la efervescencia de la semiótica de la cultura y de la antropología que le sigue a aquella impulsarán el nacimiento de una ciencia semiológica para el estudio del fenómeno teatral. Romera Castillo en Semiótica literaria y teatral en España (1988) realiza un recorrido por los orígenes de la semiótica en España cifrando sus inicios hacia finales de la década de los sesenta, sus primeros frutos a lo largo de la década del setenta y su apogeo e institucionalización en los años ochenta ${ }^{2}$ Las

\footnotetext{
${ }^{2} \mathrm{~A}$ este propósito cita el I Congreso Internacional de Semiótica e Hispanismo en el que se propondría la fundación, bajo iniciativa de Romera Castillo, de la Asociación Española de Semiótica. Romera Castillo ha llevado a cabo revisiones de cuánto se ha avanzado en semiótica teatral con posteridad como lo demuestran los trabajos, "Sobre semiótica tea-
} 
editoriales Alberto Corazón y Gustavo Gili desempeñarían una importante labor en la publicación y difusión de acercamientos semióticos de uno y otro lado de las fronteras. La influencia del estructuralismo francés deviene esencial en este punto. En la primera, se publicarían las traducciones de Elementos de semiología de Roland Barthes en 1970, de Arte y semiología de Mukarovsky en 1971 o La significación y lo significativo: estudio de las relaciones entre el signo y el valor de Charles Morris en 1974. De entre los títulos publicados por Gustavo Gili podemos apuntar el Proyecto de semiótica (1973) de Garroni, la Semiología de la representación: teatro, televisión, cómic (1978) de André Helbo o la traducción de la Estética y semiótica del cine (1979) de Yuri Lotman.

Vinculada a la hegemonía del espectador, se produce así la paulatina introducción de la semiología como disciplina idónea desde la que abordar el análisis del acontecimiento teatral, así como del texto mismo. Esta ciencia vendrá a aportar la explicación académica y rigurosa a la especificidad dramática marcada por su dualidad literaria-espectacular. Los acercamientos semióticos serán de particular interés en el estudio del trasvase de una a otra esfera, en el análisis de la transformación sígnica que se produce en el hiato que separa texto y escenario. El esquema de la comunicación de Jakobson será de enorme eficacia en su trasposición a los planos literario y espectacular del teatro. El hecho dramático ha cambiado, como también ha cambiado el modo de percibirlo. Hay, por tanto, un objeto nuevo, distinto de la enunciación del texto literario acompañado de una ilustración verista que suponía la puesta en escena realista. Los lenguajes escénicos se han desarrollado y han creado códigos no escritos. Existe una nueva gramática escénica que requiere ser indagada. Necesitamos, por tanto, un nuevo aparato crítico y metodológico que se adecúe a las necesidades del nuevo objeto. Es, por tanto, la aparición de la semiología teatral como disciplina el síntoma del cambio que se ha producido en la escena y en la concepción de la misma.

tral" (2006a) y "Bibliografía de la semiótica en España: segunda parte. Teatro (2006b)", entre otros. 
Entre las primeras aproximaciones semiológicas al ámbito teatral tenemos que citar el Análisis semiológico del lenguaje de las comedias bárbaras que lleva a cabo Joaquina Canoa, publicado originariamente por la Universidad de Santiago de Compostela en 1974³. Resulta, asimismo, de significativo valor el pionero monográfico titulado Semiología del teatro, coordinado por Díez Borque y García Lorenzo, que sale a la luz en 1975. El volumen nace con consciencia de su propia novedad ${ }^{4}$, recogiendo una serie de artículos desde diversos enfoques. Rodríguez Adrados sistematiza y clasifica los motivos eróticos del teatro griego recurrentes en forma y en significado señalando la matización o cambio de significado que adoptan en Eurípides. Castagnino reflexiona sobre las inmensas posibilidades de la semiótica para el ámbito teatral por permitir el descubrimiento en el texto literario de las claves del futuro hecho teatral, revelando el teatro como un arte radicalmente distinto. Procede tras estas deliberaciones, al estudio semiótico de un texto dramático colombiano. Luciano García Lorenzo propone un preciso análisis de los elementos paraverbales en el teatro de Antonio Buero Vallejo, deteniéndose en el gesto, la música y los objetos reclamados por la escena; mientras que André Helbo reflexiona sobre las peculiaridades de la comunicación teatral a través del análisis de Port Royal. María del Pilar Palomo estudia, a propósito de La esfinge de Unamuno, el distinto proceso comunicativo que se da cuando el receptor es un lector o un espectador, mostrando el fracaso del autor con este último, así como la manera en la que en el predominio de la función emotiva, la significación denotativa deja paso a la connotativa, y ésta a la simbólica. Díez Borque, coordinador del volumen, parte de una interesante introducción en la que plantea las peculiaridades del signo escénico para detenerse en el análisis de algunos de los elementos del teatro del Siglo de Oro desde la perspectiva que imprime la clasificación de los sistemas de signos de Corvin y Kowzan,

\footnotetext{
${ }^{3}$ Será reeditado en 1977 bajo el título Semiología de las comedias Bárbaras en la editorial Planeta.

${ }^{4}$ En la contraportada aparece la ingenua afirmación de que se trata del volumen "primero que se publica en el mundo sobre el tema”.
} 
abordando así en el valor de la palabra, de los signos externos al actor, de los kinésicos o del decorado. La esclarecedora mirada de Umberto Eco da unas claves fundamentales sobre el modo de significar del signo teatral, juzgando que para que un signo exista basta que exista una convención que permita interpretar como signo un acontecimiento, propone asimismo tres campos fundamentales de la investigación semiótica: la kinésica, la paralingüística y la prosémica, reclamando la interalimentación del análisis para la creación y de la creación para el estudio. Cesare Segre realiza un meticuloso análisis de cada uno de los signos escénicos que aparecen marcados lingüísticamente por las acotaciones en Acte sans paroles de Beckett, ordenando los elementos en instrumentos, objetos, órdenes y reacciones, y mostrando las relaciones que se establecen entre lo escrito y lo visual que interpreta y explica. Jorge Urrutia se detiene a identificar lo específico teatral, citando autorizadas voces que consideran que lo distintivo de este arte descansa en la pluricodicidad y la interrelación de signos diferentes. Enfrenta esta idea a la defendida por Grotowski en su teatro pobre quien solo juzga esencial la presencia del actor y el espectador y la particular relación que se da en el acto escénico. Reflexiona asimismo sobre las funciones del lenguaje que cobran presencia a través de las acotaciones. A estos se suman otros dos artículos que relacionan cine y teatro a cargo de András Szekfü, especialista en crítica semiológica teatral y cinematográfica, y de Aleksandr K. Zholkovskiï, doctor en Lingüística y miembro de consejo de redacción de Poetics. La entidad académica de los autores de las intervenciones críticas revela la progresiva comunicación entre el mundo universitario y el teatral. La diversidad de enfoques evidencia la juventud de esta ciencia.

Tres años después, en 1978, verá la luz otra aproximación colectiva bajo el título Elementos para una semiótica del texto artístico (Poesía, narrativa, teatro, cine). Este acercamiento semiótico al texto artístico se encuentra dividido en tres partes: una primera, a cargo de Jenaro Talens en la que plantea una perspectiva teórica general; una segunda parte, sobre semiótica literaria que engloba otro estudio de Jenaro Talens, 
en esta ocasión, sobre la "Teoría y técnica del análisis poético", y una aproximación semiótica a la narrativa que realiza José Romera Castillo en "Teoría y técnica del análisis narrativo"; la tercera parte del libro está dedicada a la semiótica del espectáculo y comprende la "Teoría y técnica del análisis teatral", a cargo de Antonio Tordera, y la "Teoría y técnica del análisis fílmico" por Vicente Hernández Esteve. De este mismo año es la Semiología de la representación de André Helbo ya citada.

El auge de la semiología dramática persiste en la década de los ochenta y permanecerá vigente hasta la década de los noventa. Bobes Naves inaugura su acercamiento semiológico al acontecimiento teatral mediante el artículo "Posibilidades de una semiología del teatro", publicado en Estudios humanísticos en 1981 (núm. 3, 1981: 11-26), aproximación que culminará con la publicación de la ya clásica Semiología de la obra dramática en $1989^{5}$. En mayo de 1982, se abre una sección a cargo de Guillermo Heras en Pipirijaina titulada "Del signo teatral" en la que se abordan estudios a este respecto de especialistas internacionales. Solo contó con dos ediciones, la dedicada a las teorías de Daniel Mesguich ("Del signo teatral. Daniel Mesguich", Heras, 1982a) y la dedicada a las de Richard Foreman ("Del signo teatral. Richard Foreman", Heras, 1982b). Son las citadas muestras de la explosión semiológico que vivió el discurso dramático del momento. Esta ciencia vendrá a aportar la explicación académica y rigurosa a la especificidad dramática marcada por su dualidad literaria-espectacular. Los acercamientos semióticos serán de particular interés en el estudio del trasvase de una a otra esfera, en el análisis de la transformación sígnica que se produce en el hiato que separa texto y escenario. El esquema de la comunicación de Jakobson será de enorme eficacia en su trasposición a los planos literario y espectacular del teatro.

Hacia la mitad de la década de los setenta, y gracias a las diferentes

\footnotetext{
${ }^{5} \mathrm{El}$ interés de esta estudiosa por la perspectiva semiológica en sus acercamientos al teatro ha persistido en el tiempo, muestra de ello sería la publicación de Semiótica de la escena: análisis comparativo de los espacios dramáticos en el teatro europeo en Arco / Libros en 2001.
} 
tensiones ejercidas por uno y otro elemento escénico, podemos hablar de la escena como lugar de integración y diálogo entre los diferentes lenguajes escénicos que gozan ya de plena autonomía artística. El nuevo teatro deviene fundamentalmente comunicación con el espectador. Emancipados, pues, los diferentes lenguajes que se dan cita en la escena, será el espectador interpretante el que se sitúe en el centro, como fuerza activa y dinámica.

El protagonismo alcanzado por el espectador en estos momentos es paralelo al que conquistara el lector unos años antes en la nueva concepción de la narrativa sobre la que Castellet reflexiona en La hora del lector (1957). La pérdida del punto de vista autoritario y absolutista del narrador o el oscurecimiento de la expresión eran síntomas reveladores de la progresiva desaparición del autor tras la escritura misma. Paralelo proceso acontece en la escena del momento, la voz del autor será ya una más de las escrituras enfrentadas que se convocan y enfrentan en el escenario.

Desde el ensayo de Barthes "La muerte del autor" (1968) comprendemos mejor el momento de la poética ${ }^{\mathrm{e}}$ scénica y dramatúrgica que nos ocupa. Supone una contigüidad evidente. El paralelismo con el ensayo barthesiano se hace obvio, constituyendo ambos terminales de una misma evolución, aporta así el texto de Barthes buena luz a la comprensión del fenómeno teatral. El ensayo revela el fin del reinado del autor y el comienzo del gobierno del texto, la conquista de su autonomía como ente significante que no se cierra en un significado definitivo. Asevera Barthes que

\footnotetext{
${ }^{6}$ Este ensayo nace de la evolución y desarrollo de la ponencia "Escribir: ¿verbo intransitivo?" que leerá Roland Barthes en el marco del seminario internacional, "Los lenguajes críticos y las ciencias del hombre”, en el Centro de Humanidades Johns Hopkins en Baltimore, del 18 al 21 de octubre de 1966. Será publicada junto al resto de intervenciones en un volumen con el nombre del seminario en 1970 en Barral Editores. En este ensayo afirmaba ya que "paradójicamente, en el momento en el que el verbo escribir parecía convertirse en intransitivo cuando su objeto, el libro o el texto, adquirió una importancia particular" (en Donato y Macksey, ed., 1972: 160-161). La fecha de redacción de "La muerte del autor es 1968, citaremos por El susurro del lenguaje. Más allá de la palabra y la escritura (1987).
} 
la escritura es la destrucción de toda voz, de todo origen, [...] es ese lugar neutro, compuesto, oblicuo, al que va a parar nuestro sujeto, el blanco-y-negro en donde acaba por perderse toda identidad, comenzando por la propia identidad del cuerpo que escribe (1987: 65).

La escena del momento se levanta contra la jerarquía del autor dramático mediante el abandono de los textos prefijados y contra la recién conquistada figura del director mediante la fórmula de la creación colectiva. El paralelismo con la crisis de la representación que atraviesan las vanguardias escénicas se evidencia cuando apunta que

escribir ya no puede seguir designando una operación de registro, de constatación, de representación, de pintura -como decían los clásicos-, sino que más bien es lo que los lingüistas, siguiendo la filosofía oxfordiana, llaman un performativo, forma verbal extraña - que se da exclusivamente en primera persona y presente - en la que la enunciación no tiene más contenido más enunciado- que el acto por el cual ella misma se profiere (1987: 68-69).

La consustancial performatividad del acontecimiento teatral se extrema en un sentido de la escena que no representa un mundo anterior o exterior a sí misma, sino que se convierte en mundo escindido y autónomo. Si el teórico francés postuló en tal ensayo que el nacimiento del lector se pagaría con la muerte del autor; la supresión y muerte del autor dramático, así como la del director escénico conllevarían asimismo el nacimiento de un espectador nuevo, activo e interpretante. Afirma Barthes que:

existe un lugar en el que se recoge toda esa multiplicidad, y ese 
lugar no es el autor, como hasta hoy se ha dicho, sino el lector: el lector es el espacio mismo en que se inscriben, sin que se pierda ni una, todas las citas que constituyen una escritura; la unidad del texto no está en su origen, sino en su destino (1987: 71).

El texto no se halla clausurado en su emisión, sino que requiere de la recepción para que el espectador le dé forma y unidad. El teatro refuerza su concepción comunicacional en estos momentos en los que los únicos elementos imprescindibles son actor y espectador, polos del arco comunicacional que constituirá la puesta en escena, entre los que la soberanía terminará recayendo en el segundo en tanto unifica e interpreta la conjunción de escrituras que supone la puesta en escena.

\section{REFERENCIAS BIBLIOGRÁFICAS}

A.A. V.V. (1978). Elementos para una semiótica del texto artístico. Madrid: Cátedra.

ARJONA, R. (1976). “Divinas palabras, de Valle Inclán, por la compañía de Nuria Espert". $A B C, 11$ de enero, 35. Recuperado de http:// hemeroteca.sevilla.abc.es/nav/Navigate.exe/hemeroteca/sevilla/ abc.sevilla/1976/01/11/049.html [20/05/2018].

BARTHES, R. (1970). Elementos de semiología. Madrid: Alberto Corazón. (1972). “Escribir: ¿verbo intransitivo?”. En Los lenguajes críticos y las ciencias del hombre, Eugenio Donato y Richard Macksey (eds.), 160-161. Barcelona: Barral Editores.

BOBES NAVES, M. ${ }^{a}$ C. (1981). "Posibilidades de una semiología del teatro". Estudios Humanísticos 3, 11-26.

(1987). Semiología de la obra dramática. Madrid: Taurus.

(2001). Semiótica de la escena: análisis comparativo de los espacios dramáticos en el teatro europeo. Madrid: Arco / Libros. 
CANOA, J. (1974). Análisis semiológico del lenguaje de las Comedias bárbaras. Santiago de Compostela: Universidad de Santiago de Compostela.

CASTELLET, J. M. a (1957). La hora del lector. Barcelona: Península. DÍEZ BORQUE, J.M y GARCÍA LORENZO, L. (eds.) (1975). Semiología del teatro. Barcelona: Planeta.

HELBO, A. (1978). Semiología de la representación: teatro, televisión, cómic. Barcelona: Gustavo Gili.

HERAS, G. (1982a). "Del signo teatral. Daniel Mesguich”. Pipirijaina 22, mayo, 69-78.

(1982b). "Del signo teatral. Richard Foreman". Pipirijaina 23, julio, 78-80.

JANSA ANADÓN, M. (1974). “Un grito de alarma”. Pipirijaina 4, junio, 34.

JAUSS, H. R. (1970). La historia de la literatura como provocación a la ciencia literaria. Madrid: Gredos.

LAÍN ENTRALGO, P. (1970). "Valle-Inclán", Nel mezzo del cammin. I. Gaceta Ilustrada 712, 31 de mayo, 20.

LÁZARO CARRETER, F. (1977). "Divinas palabras, espectáculo de Víctor García". Gaceta Ilustrada 1064, 27 de febrero, 8.

LLOVET, E. (1976). "Devorar a García Lorca". El País, 26 de septiembre. Recuperado de https://elpais.com/diario/1976/09/26/ cultura/212540414_850215.html [03/04/2018].

(1976). "Una auténtica queja andaluza". El País, 26 de octubre. Recuperado de https:/lelpais.com/diario/1976/10/24/ cultura/214959607_850215.html[03/04/2018].

(1977). "Espert-García ofrecen un monumental espectáculo". El País, 30 de enero. Recuperado de https://elpais.com/diario/1977/01/30/ cultura/223426808_850215.html [03/04/2018].

LOTMAN, I. (1979). Estética y semiótica del cine. Barcelona: Gustavo Gili.

MIRALLES, A. (1975). “Alias Serrallonga de Els Joglars”. Primer Acto 
90-95, 179-180-181.

MONLEÓN, J. (1967).” Don Ramón: esperpento y farsa". Triunfo, 4 de febrero, 59. Recuperado de http://www.triunfodigital.com/ mostradorn.php? a\%F1o $=X X I \&$ num $=244 \&$ imagen $=54 \&$ fec ha=1967-02-04 [03/04/2018].

(1971). "Yerma, el teatro de lo insólito". Triunfo, 11 de diciembre, 36-39. Recuperado de http://www.triunfodigital.com/mostradorn. php $?$ a\%F1o=XXVI\&num $=480 \&$ imagen $=36 \&$ fech $a=1971-12-11$ [03/04/2018].

(1973). “Mary d'Ous en Madrid”. Triunfo, 5 de mayo, 69. Recuperado de http://www.triunfodigital.com/mostradorn.php? a\%F1o=XXVII $\&$ num $=553$ \&imagen $=69 \&$ fech $a=1973-05-05$ [03/04/2018].

(1980). "La visión de Lavelli". Primer Acto 186, 27.

MORRIS, Ch. G. (1974). La significación y lo significativo: estudio de las relaciones entre el signo y el valor. Madrid: Alberto Corazón.

MUKAROVSKY, J. (1971). Arte y semiología. Madrid: Alberto Corazón. NIEVA, F. (1973). “¿Quién eres tú, Mary D’Ous?”. Primer Acto 15, 4-8.

PREGO, A. (1971). Yerma, de Víctor García en la comedia. $A B C, 1$ de diciembre, 81-82.

ROMERA CASTILLO, J. (1988). Semiótica literaria y teatral en España. Kassel: Reichenberger. (2006a). "Sobre semiótica teatral". En Literatura, teatro y semiótica: Método, prácticas y bibliografía, 193-225. Madrid: UNED.

(2006b ). "Bibliografía de la semiótica en España: segunda parte.

Teatro". En Literatura, teatro y semiótica: Método, prácticas y bibliografía, 499-524. Madrid: UNED.

Recibido el 5 de marzo de 2018.

Aceptado el 11 de junio de 2018. 
